\title{
Evaluation of the 2009 Rehearsal and lessons learned for the 2011 Census
}

Neil Townsend

Office for National Statistics

\section{Abstract}

A rehearsal for the 2011 Census was held in October 2009. This article provides a detailed summary and evaluation of this rehearsal, highlighting the successes, areas requiring improvement, and improvements planned for 2011 as a result of key lessons learned. 


\section{Contents}

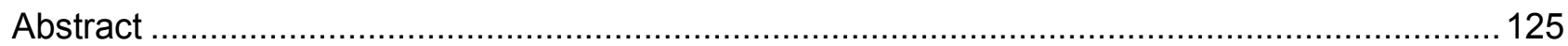

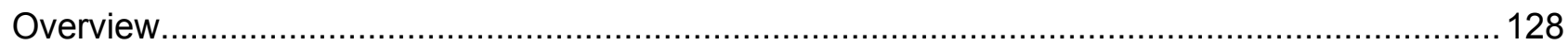

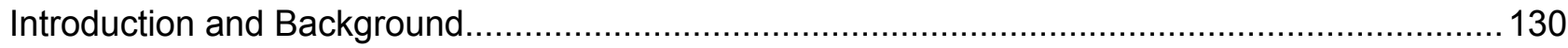

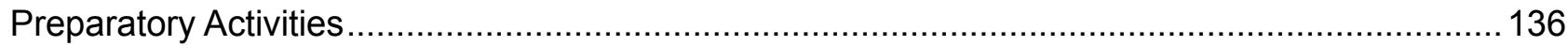

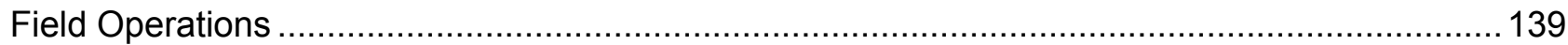

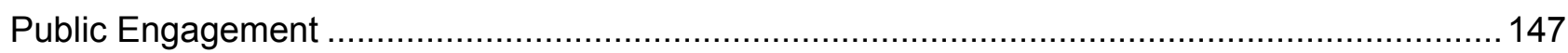

Conclusions and ONS response to the rehearsal .......................................................... 151

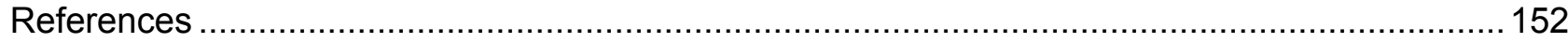

\section{List of figures}

Figure 1 Age of rehearsal respondents and estimated population in rehearsal areas ......... 134

Figure $2 \quad$ Ethnicity of Newham rehearsal respondents ................................................. 135

Figure $3 \quad$ Rehearsal respondents and non-respondents by age group ............................ 135

Figure $4 \quad$ Rehearsal respondent and non-respondent households by tenure...................... 136

Figure $5 \quad$ Return method by age group ......................................................................... 141 


\section{List of tables}

Table 1 Households per rehearsal area 131

Table 2009 Rehearsal final return rates by hard-to-count strata .................................. 133

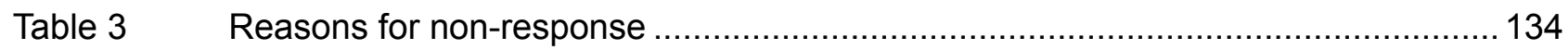

Table $4 \quad$ Effect of delivery method on returns ................................................................ 140

Table $5 \quad$ Effectiveness of follow-up by hard-to-count strata............................................... 142

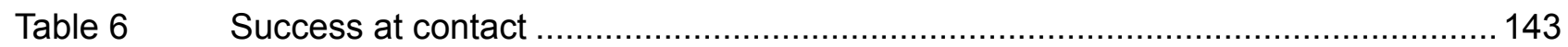

Table $7 \quad$ Return rates after 9 November in Newham .................................................. 144

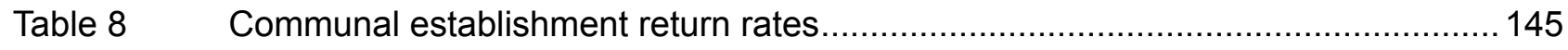

Table $9 \quad$ Likelihood to complete a return before and after the publicity campaign ............... 149 


\section{Overview}

\section{Aims of the rehearsal}

ONS's overall objective from the 2009 Census Rehearsal was to confirm the viability of the final 2011 Census field procedures and supporting systems by integrating them and running them in the same timescale as the 2011 Census. It wanted to minimise the risk of failure in 2011 particularly by rehearsing new and innovative procedures and systems.

The main areas to prove were that:

- the address register created was of sufficient quality to rehearse the field operation

- the field procedures for delivery and collection of questionnaires to both households and communal establishments (CEs) worked effectively

- the management structures for the field operation were effective

- the recruitment, pay and training of the field staff worked

- the key systems to support the field and public, questionnaire tracking and internet data capture were effective

- our engagement with local authorities and communities was sufficient

In addition, the rehearsal gave ONS, its partners and suppliers experience of the operation.

ONS's expectation was that plans would be proven to work, and areas identified where improvements for 2011 needed to be made.

\section{Successes}

The rehearsal successfully demonstrated that field procedures and supporting systems worked, and worked together.

No significant problems were encountered with any of the systems:

- questionnaires were printed and delivered successfully

- questionnaire receipting and tracking worked: centrally and locally, there was accurate information on which addresses had (and had not) returned a questionnaire

- internet data capture, online help and the contact centre all ran smoothly

- field staff were recruited and trained with the required skills in the required numbers

- field staff were paid accurately, and on time

- the publicity campaign reached the general public and the key population groups

\section{Areas for improvement}

Despite all the systems working, having sufficient staff and the publicity and engagement strategies, the questionnaire return rate was not as high as had been expected. The final return rate for the rehearsal was 41 per cent, around 10 per cent less than expected. This shortfall was observed across all areas, but was particularly marked in the geographic areas that had been identified in advance as being the most difficult to count. In addition, particular problems were experienced with the return rate from students in halls of residence. 
Although generally the systems and processes worked, there were some problems, including:

- the targeting of follow-up resources at areas within local authorities with poor return rates was not sufficiently strong

- area managers and census coordinators did not have enough time to complete all the tasks required of them.

Additionally, internet return rates were lower than expected, at 8 per cent, rather than the expected rate of around 25 per cent.

\section{Improvements for 2011 arising from the rehearsal}

Given the findings from the rehearsal, most of the changes being implemented are designed to improve return rates, particularly in the most difficult geographic areas. Some other minor changes to processes and systems are needed, but not major re-designs.

Analysis of the reasons for non-response shows that the most common reason for not making a return was the rehearsal not being compulsory; people were not willing to fill in a questionnaire for a voluntary exercise.

Reasons for non-response that had been anticipated (general anti-government attitudes and concerns about data protection/security) did not feature highly as reasons for non-participation.

The characteristics of non-respondents to the rehearsal (for example, young people and non-white ethnic groups) will feed into community liaison and publicity plans.

In addition to doorstep follow-up, a number of initiatives were tried to raise return rates, including extra publicity, sending out replacement questionnaires, and sending reminder letters. Reminder letters were found to be particularly effective, increasing return rates by nearly 4 per cent.

However, concerns about the return rates remain, particularly when combined with other evidence that suggests the general environment for survey activity is getting harder; return rates for the ONS Labour Force Survey have been falling by about 1 per cent per year over the last decade.

In light of these issues, improvements are being made to plans for 2011. The main ones are:

- increasing the resources in follow-up by putting in approximately half a million extra hours

- putting a greater proportion of resources into areas where achieving high return rates are anticipated as being more challenging

- increasing the resources put into managing the field operation particularly in challenging areas, by increasing the number of area managers from 118 to 157 and reducing the average number of staff a coordinator manages from 15 to 12 in the more challenging areas

- increasing publicity spend

- increasing community engagement activities

In order to fund these additional initiatives and resources, the design has been reviewed to ensure it makes the most effective use of resources. As a result the most significant change is to reduce hand delivery of census questionnaires to communal establishments only. ONS had planned to hand deliver questionnaires to 5 per cent of households, but have found it to have a minimal effect on return rates and that resource would be better spent on follow-up. As well as reducing hand delivery, non-compliance activity has been scaled back. 


\section{Introduction and Background}

\section{Introduction}

The purpose of this article is to outline the headline findings from the rehearsal:

- what worked well

- what could be improved

- resulting design changes being made to achieve these improvements

Extensive analysis has been undertaken of the rehearsal. This article concentrates on how the high level design worked and issues likely to be of particular interest to external stakeholders.

\section{Background}

ONS decided to conduct a rehearsal before the 2011 Census (as it has done before previous censuses) $)^{1}$ to assure itself and external stakeholders that the processes designed for 2011 work.

A number of significant design changes to the census process for 2011 have been made in response to lessons learned from 2001 , technological change and changes in society. In addition ONS is working with a number of external partners to deliver the census.

The 2009 Rehearsal was the first chance to work with near to final systems and with chosen suppliers for the main 2011 Census. The 2011 design is more complicated and more reliant on the integration of IT systems than in previous censuses. This meant that ONS wanted to ensure the rehearsal systems were as close as possible to those for 2011 and all interfaces were sufficiently rehearsed.

The rehearsal was deliberately delayed six months from original plans so that better developed systems could be rehearsed (in the 1999 Rehearsal - ahead of the 2001 Census - many of the final systems were not built and the team had worked with suppliers for less time).

The 2009 delay meant the time of year for rehearsal did not reflect that of the census (which impacted the field operation). It also reduced time to make significant system and design changes without seriously risking delivery for 2011.

Some aspects of a real census cannot be replicated in a rehearsal, most significantly:

- the small scale and localised nature of the rehearsal (this particularly limits publicity options and media coverage)

- the compulsory nature of the census (public cooperation is relied on in a voluntary rehearsal and non-compliance processes cannot be trialled)

\section{Geographic scope and size of rehearsal}

The rehearsal areas were selected to give a range of area types and specifically to include:

- a large contiguous area

- areas with both one and two tier local government structures

- an area in London with a multi-cultural population

- an area in North Wales with a high population of Welsh speakers 


\section{Table $1 \quad$ Households per rehearsal area}

\begin{tabular}{lr}
\hline Area & $\begin{array}{r}\text { Number of } \\
\text { households }\end{array}$ \\
\hline Isle of Anglesey $^{1}$ & 33,547 \\
Lancaster $^{*}$ & 61,725 \\
Newham & 38,618 \\
Total & $\mathbf{1 3 3 , 8 9 0}$ \\
\hline
\end{tabular}

1 Whole local authority

- areas that included particular communal establishment types (namely a military base, a large hospital, university halls of residence, a prison and traveller sites, as well as a good number of care homes and hotels)

The areas selected were across three local authorities: all of Anglesey, Lancaster and parts of Newham. In Newham, areas were selected which were considered representative. Newham suggested some areas as being particularly challenging and these were also added. The number of households contained within each area is detailed in Table 1.

\section{Birmingham small scale test}

In parallel to the rehearsal, a small scale test (SST) was undertaken in Birmingham. While this does not formally sit within the rehearsal scope it utilised most of the procedures and processes delivered within the rehearsal. The figures quoted in the main text of this article exclude Birmingham.

\section{Overview of rehearsal operation}

This section briefly summarises the rehearsal process. Except where identified, this is the same as the design for the 2011 Census.

\section{The address register}

There is no single national address list that fulfils the requirements of the census. Therefore, an address register was developed for the rehearsal that brought together addresses from other data sources that had either coverage of households (for example the Royal Mail Postal Address File and the National Land and Property Gazetteer) or coverage of a particular type of establishment (for example hospitals and care homes, or caravan parks). This information was supplemented by field checks and query resolution by local authorities and address list suppliers.

The address register underpins the entire census design and operation. Addresses were printed on each questionnaire before delivery. The address register was used to populate the questionnaire tracking (QT) system. This enables the tracking of every questionnaire from delivery to processing. The QT system tracked each questionnaire by means of a unique identification number and barcode and provided up to date information on progress of the operation and actions for individual addresses (for example, the delivery of a replacement questionnaire).

\section{Questionnaire delivery}

All households in the rehearsal received a census questionnaire, either through the post or delivered by hand, along with an information leaflet and a pre-paid envelope for returning their 
completed questionnaire. Communal establishments (managed accommodation such as care homes and university halls of residence) were hand delivered a communal establishment questionnaire and individual questionnaires for each resident. In Anglesey, both English and Welsh language questionnaires were sent out to every household.

\section{Return and collection of questionnaires}

Householders completed their paper questionnaires and returned them by post or completed the census online. Household returns via post and the internet were receipted daily and this information uploaded onto the QT system.

Questionnaires were collected by special enumerators in communal establishments. Individual residents also had the option of completing their questionnaire online.

\section{Follow-up}

Census collectors were employed to visit households that had not returned a questionnaire, to encourage and assist householders to respond. Collectors prioritised the areas with the lowest return rates. The follow-up started 10 days after rehearsal day on 21 October 2009 and carried on until six weeks afterwards (20 November 2009). In the census, non-responders will be subject to non-compliance procedures. In the rehearsal no further action could be taken if a householder refused to participate.

\section{Census coverage survey}

As planned for the 2011 Census, the rehearsal was followed with a Census Coverage Survey (CCS). The CCS is a short doorstep interview of approximately 1 per cent of households that is used to estimate the number of households and people not counted in the census. It is vital to producing an accurate estimate of the population. The CCS design is very similar to that successfully employed in 2001 . The CCS achieved a response rate of 79 per cent and, overall, the design worked well with no significant issues although some detailed refinements of the recruitment and training are being taken forward.

\section{Assistance completing the questionnaire}

The questionnaire is straightforward to complete, but some households needed assistance due to language challenges, illiteracy or disability.

The online help facility provided a range of information explaining the benefits of the census, what the information is used for and answers to frequently asked questions.

The telephone helpline provided answers to similar questions, arranged help visits to households and provided translation facilities. Translation leaflets in 35 languages were available from field staff, or to download, from the online help facility.

\section{Data processing}

Returned paper questionnaires were sent to the census data processing site where they were scanned. Free text responses (write-in answers) were reviewed and coded into a number of classifications. The data were then passed to ONS. In 2011 this data will be used to produce the outputs. No outputs are produced from the rehearsal; the data are used for internal purposes to test the capture and coding process and the other later statistical processes. 


\section{Return rates achieved}

\section{Introduction}

An indicator to whether procedures and systems worked is the return rates achieved, although given the rehearsal was voluntary, they are not an explicit indicator of success for the 2011

Census. Return rates indicate:

- the public's underlying attitude to the census and completing official documentation

- the simplicity and clarity of the task

- the effectiveness of the publicity, the community engagement activities in increasing awareness and positive attitudes to the census

- the effectiveness of the field staff in making contact with, and subsequently assisting and persuading, the public to take part

\section{Return rate analysis}

The overall return rate for the rehearsal was 41 per cent. Individual local authority return rates were:

- Anglesey 49 per cent

- Lancaster 48 per cent

- Newham 28 per cent

ONS has stratified the country into five groups according to estimated response levels to the census. The 40 per cent predicted best responding areas are hard to count (HTC) 1, the next 40 per cent $\mathrm{HTC} 2$, the next 10 per cent $\mathrm{HTC} 3$, the next 8 per cent $\mathrm{HTC} 4$ and the remaining 2 per cent (where the lowest return rates are expected) HTC5. Breaking the rehearsal return rates down by the hard to count strata gives the following results:

\section{Table 2009 Rehearsal final return rates by hard-to-count strata}

\begin{tabular}{lr}
\hline Hard to count strata & $\begin{array}{r}\text { Return rate } \\
\text { (per cent) }\end{array}$ \\
\hline HTC1 (easiest) & 52 \\
HTC2 & 42 \\
HTC3 & 37 \\
HTC4 & 28 \\
HTC5 (Hardest) & 25 \\
All areas & $\mathbf{4 1}$ \\
\hline
\end{tabular}

This trend is exactly what was expected and demonstrates that the HTC classifications were accurate. The rehearsal areas did not reflect the make-up of the country in terms of the proportions of each hard to count strata. For example, Newham made up 29 per cent of the rehearsal and was exclusively HTC4 and HTC5. These areas make up only 10 per cent of England and Wales as a whole. Weighting the return rates to reflect the make-up of England and Wales, gives an overall return rate of 44 per cent. 


\section{Reasons for low return rates}

ONS ran a survey of non-responding households to understand why they did not respond. The following table shows the reasons given for not participating (excluding households that claimed not to have received a questionnaire or to have returned it):

\section{Table 3 Reasons for non-response}

\begin{tabular}{lrr}
\hline Reason & Number & Per cent \\
\hline Understanding of questionnaire and language issues & 70 & 7 \\
Privacy, confidentiality issues & 124 & 12 \\
Personal reasons e.g. health/age & 157 & 16 \\
Voluntary exercise/apathy & 552 & 56 \\
Other & 91 & 9 \\
Total & $\mathbf{9 9 4}$ & $\mathbf{1 0 0}$ \\
\hline
\end{tabular}

This shows that the majority of non-responders did not return their questionnaire because the rehearsal was voluntary. Despite breaches of government security publicised widely in the media it appears that worries about the confidentiality of information given are relatively low. Similarly, despite the fact the rehearsal was subject to Royal Mail industrial action, this did not deter participation.

\section{Nature of respondents and non-respondents}

The characteristics of respondents and non-respondents have been analysed. Figure 1 compares the age profile of rehearsal respondents to the 2008 ONS mid-year population estimates.

This suggests that older age groups were more likely to respond to the rehearsal. This is consistent with the 2001 Census where young adults had the highest levels of non-response.

\section{Figure 1 Age of rehearsal respondents and estimated population in rehearsal areas}

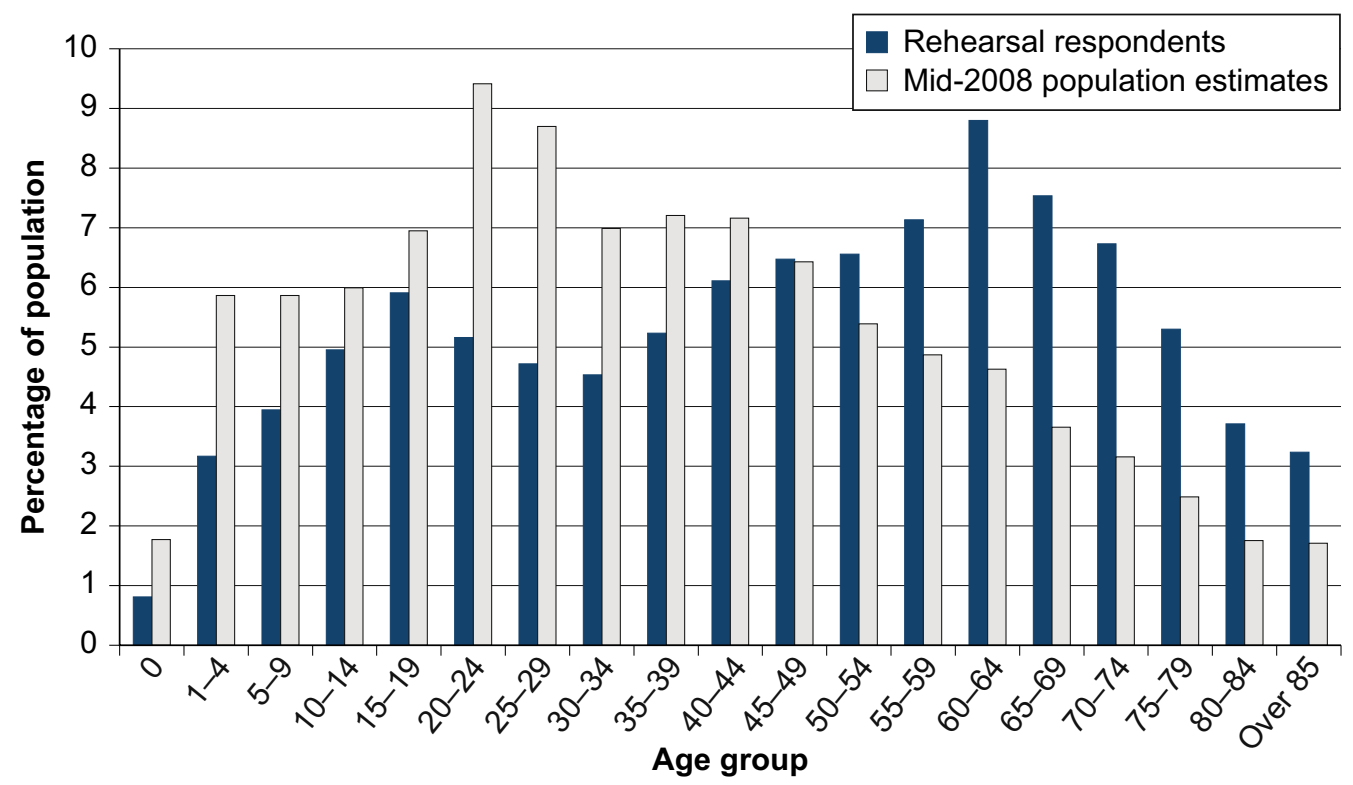




\section{Figure 2 Ethnicity of Newham rehearsal respondents}

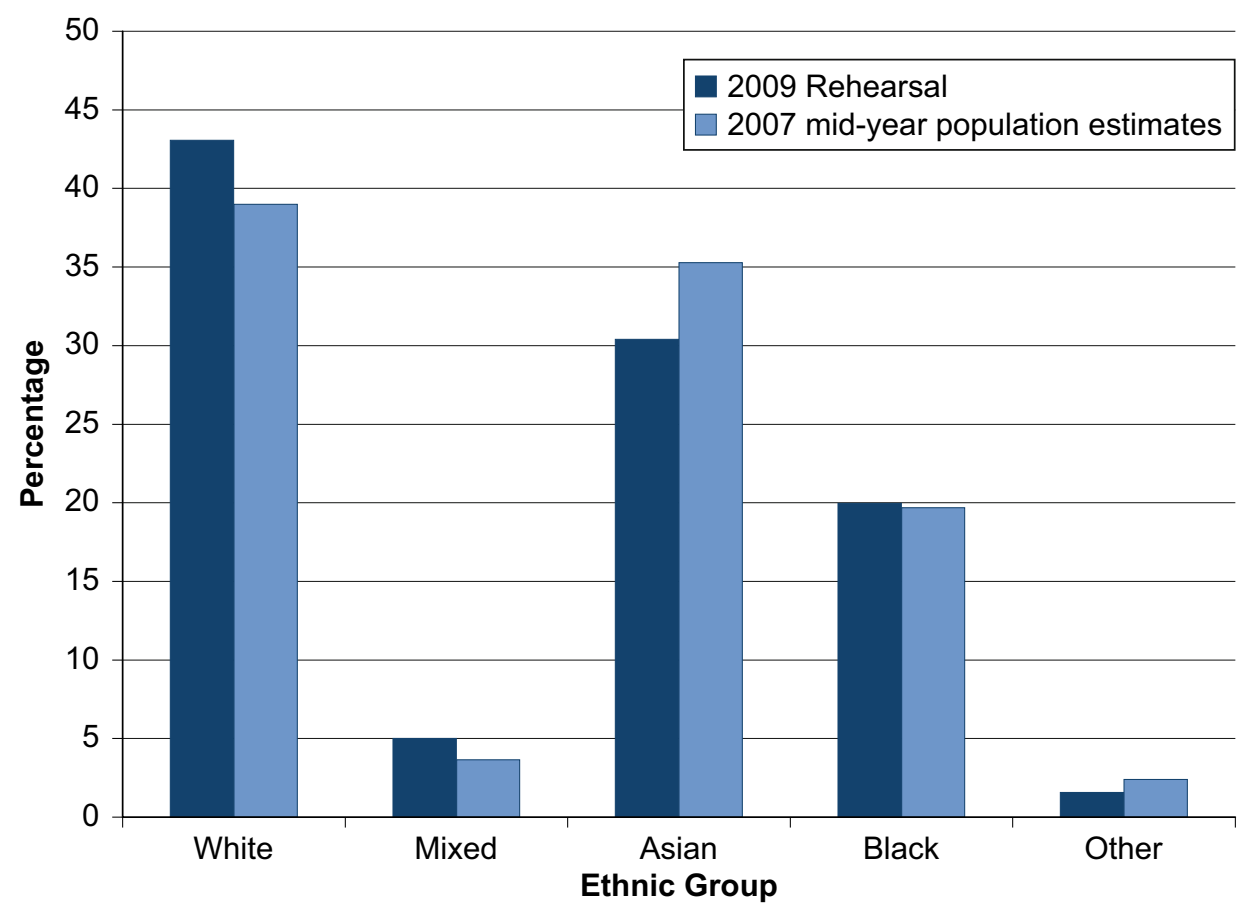

Figure 2 compares the ethnicity of rehearsal respondents to mid-year estimates and shows that the ethnicity of respondents was similar to mid-year estimates. This is done for Newham only, as the residents of the other two areas were overwhelmingly white British.

Figure 3 shows that the rehearsal non-respondents were predominantly from younger age groups (the figures for non-respondents are based on people who were included in the CCS but did not respond to the rehearsal).

Figure 4 compares the proportion of households, by tenure type, that responded to the CCS but not the rehearsal, to rehearsal respondents. The proportion of households found in the CCS who

\section{Figure 3 Rehearsal respondents and non-respondents by age group}

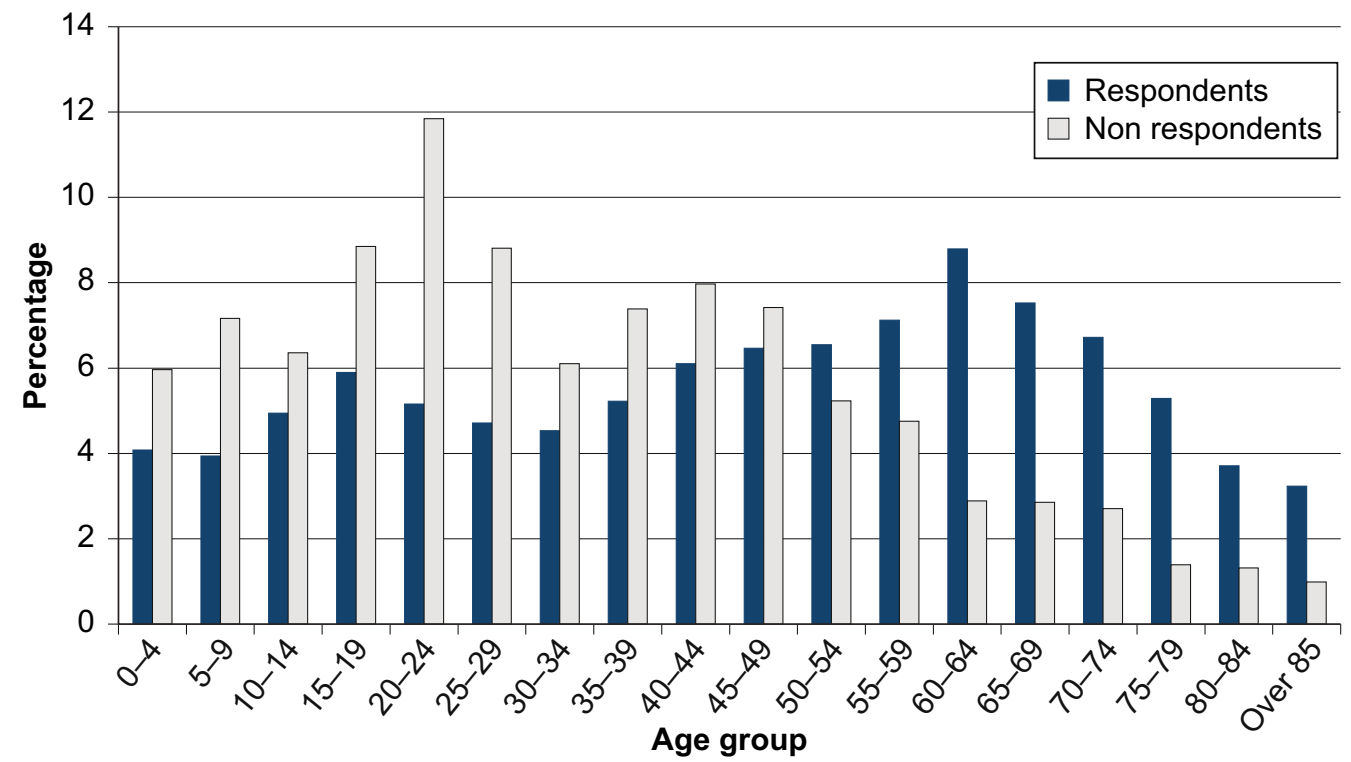




\section{Figure 4 Rehearsal respondent and non-respondent households by} tenure

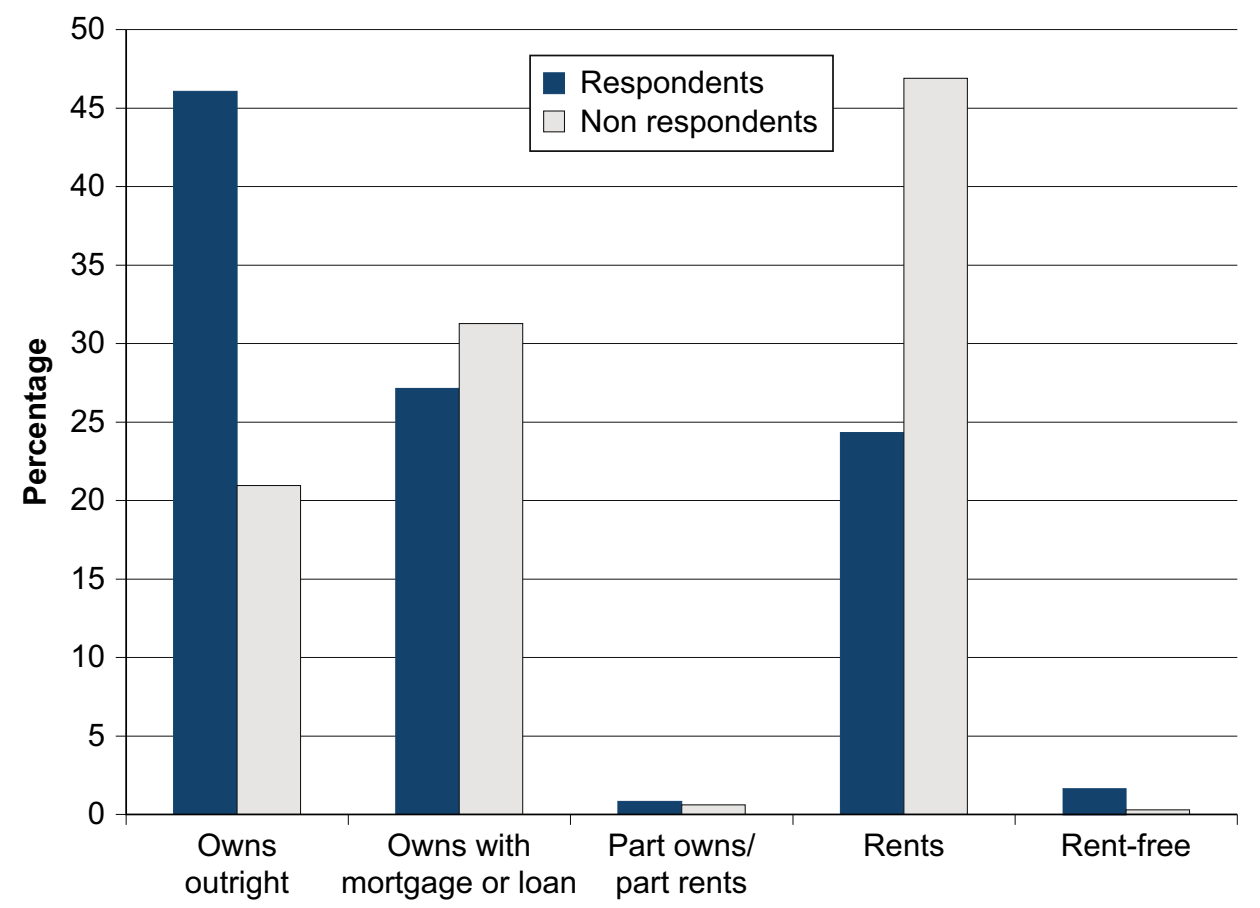

rent their property was much greater than in the rehearsal, which suggests that those who rent feature disproportionately highly among non-respondents.

\section{Preparatory Activities}

This section covers development of the address register and printing of questionnaires.

\section{Address register development}

\section{Introduction}

A high quality address register is critical for the 2011 Census. The address register underpins the pre-printing of questionnaires for delivery and the tracking of questionnaires through all stages of the census.

The address list used for the rehearsal was of much lower quality than for the census because:

- the list was dependent upon an early version of the match between the Royal Mail PAF and the National Land and Property Gazetteer - a number of improvements have been made in the meantime, particularly around complex flat matches

- it did not make use of late changes to the address register and so was not so up-to-date as the list will be in 2011

- it could not take account of input from data suppliers or local authorities

- it was based on a simple match rather than the balancing of the match and supplementary evidence that will determine the 2011 list 
This was considered workable as the objective of the rehearsal was to rehearse the field procedures and systems rather than assess the quality of the address register. Nonetheless there are lessons to be drawn from the results.

Work continues on analysing the resolutions provided by data suppliers and rehearsal local authorities.

The accuracy of the address register needs to be assessed both in terms of under-coverage (addresses missing) and over-coverage (duplicate or spurious addresses included on the list).

\section{Under-coverage}

There are two indications of under-coverage available. The first is new addresses identified during the operation. There were very few of these: only 177 found in the field and six reported by householders. This represents under-coverage of less than 0.3 per cent. However the field operation concentrates on getting responses back, not finding new addresses. The voluntary nature of the rehearsal means people were less likely to identify themselves, so this measure cannot be relied upon.

A more reliable measure is provided by comparing the address list with that compiled for the Census Coverage Survey (CCS). In the latter exercise, field staff compiled their own list for selected postcodes. The CCS list was matched against the list of addresses used for delivery.

This method is subject to significant uncertainty:

- the CCS list is developed from scratch. It is inevitable that some addresses will be described differently by CCS field staff from they way they appear in national lists. This will affect the quality of the match

- matching between the delivery address list and the CCS list is done by both automatic and manual matching using the address only.

- a difference in addresses does not equate to under-coverage. A questionnaire with a different version of an address may still end up being delivered successfully.

For all these reasons, limited matching will inevitably over-estimate under-coverage.

To date, results from Lancaster and Newham have been compared; from this the maximum level of under-coverage has been estimated to be 3 per cent in Lancaster and 7 per cent in Newham. Results from Anglesey are still being assessed but are expected to be closer to 9 per cent. This seems to be as a result of the difficulties in matching due to bilingual addresses rather than actual missing addresses. The enhanced design of the address register for 2011 (see below) suggests under-coverage will be significantly lower than this.

\section{Over-coverage}

Over-coverage is less of a concern than under-coverage, but is still wasteful of both postage and follow-up resource so needs to be minimised.

Over-coverage can be measured by the number of addresses that were identified as invalid during the field operation. In the rehearsal this amounted to 2.2 per cent overall. These were mainly duplicate addresses and business addresses. Given the nature of change (especially in Newham) and the time lag between address list cut and rehearsal day, many addresses on the list had been demolished. 
Another possible measure of over-coverage is the proportion of questionnaires returned as undeliverable from Royal Mail - although, again, this is an imperfect measure. A total of 2.3 per cent of questionnaires were returned as undeliverable. Many of the undelivered addresses were demolished. A further large number of undelivered addresses were multiple addresses at a single address point (for example, caravan parks and blocks of flats).

\section{Improvements for the 2011 Census}

The levels of under-coverage and over-coverage identified by these measures are much higher than will be acceptable for the census. Steps currently being taken and those planned over coming months, will deliver a register to the quality required. The high level approach to developing the address register consists of the following steps:

- matching between the key national sources - The Postcode Address File/Address Layer 2 (PAF/ AL2) and the National Land and Property Gazetteer (NLPG) - using an improved methodology for matching and categorising addresses across the sources

- consulting both the suppliers of these lists and local authorities on anomalies that arise from this matching process

- supplementing this with a field check of around 15 per cent of the country where there are concerns about the complexity and quality of address lists (by 356 ONS contracted staff for four months from May to August 2010)

- building rules so that an evidence-based approach to decisions about which addresses should be sent a questionnaire can be applied. This process will include use of improved business rules to filter out non-residential addresses and to balance different sources of data against each other

Quality will be further improved through:

- significant recent improvements to the quality of source products - most notably in completeness and the application of classifications within the NLPG

- a reduced time lag in producing the register and inclusion of supplier change and 'late intercept' data, to ensure the timeliness of the list and by having a late supplementary print run.

Data suppliers and local authorities have provided their input on an earlier match but the address register is still very much under construction. Work continues on refining the match, finalising plans for the address check and critically, deciding on the rules to be used to draw the final list.

\section{Printing}

\section{Introduction}

The 2011 Census design means the questionnaire printing process is more complex than in the past. Each questionnaire has to be overprinted with a unique address, bar-code and Internet Access Code (IAC). After printing, they also need to be appropriately packaged, pairing the corresponding English and Welsh language questionnaires for each address in Wales.

\section{Results}

Despite the significant complexities of overprinting, the printing operation worked smoothly overall for the 2009 Rehearsal and the questionnaires met quality and operational requirements. 
Overprinting of questionnaires with addresses, barcodes and IACs included manual and automatic quality control processes. The automatic process worked well but the manual process missed about 40 questionnaires with duplicate barcodes and IACs that were produced and distributed to field staff.

This problem was spotted very early in the operation. All questionnaires that could be affected were individually checked for duplication and removed from the field as necessary.

\section{Actions being taken}

The following changes have been put into place for 2011:

- quality control procedures at the printer have been reviewed and additional staff brought in to manage the process

- the printing process has been brought forward a month to allow more time for the quality assurance process and as a contingency for problems

No other significant changes are planned for 2011.

\section{Field Operations}

\section{Delivery of questionnaires}

\section{Design of process}

Questionnaires were delivered through two different methods: post (via Royal Mail) and hand delivery. All questionnaires to communal establishments were hand delivered by field staff, as were around 5 per cent of all household questionnaires (in a sample of areas in Newham where hand delivery was expected to offer the most benefit).

\section{Results - post out}

The rehearsal post out operation was completed to timetable, finishing one week before rehearsal day with no significant problems encountered. One day of localised industrial action by postal staff took place in Newham during postal delivery. Royal Mail mitigated the impact of this by doubling the volume of questionnaires delivered the previous day, ensuring that all deliveries were completed to timescale.

\section{Undeliverable questionnaires}

As covered above, over 2 per cent of questionnaires were returned from Royal Mail marked as 'undeliverable'. The accuracy of the address register will have had an impact on the number of undelivered addresses. However, a sample of addresses with undelivered questionnaires was checked and 13 per cent were found to be valid addresses. A questionnaire returned as 'undeliverable' by Royal Mail does not necessarily mean a non-existent address.

In 2011 the addresses of all questionnaires returned as 'undeliverable' will be identified and checked in the field before the census.

\section{Results - hand delivery}

In 2011 the census design retained a small proportion of hand delivery in areas where there was evidence of large households, or where contact at delivery may have a greater impact on response, or where there were concerns about the quality of the address register. Accordingly 5 per cent of households in the rehearsal had questionnaire hand delivered. Although the actual hand delivery process worked (contact rates were 63 per cent), it did not have the anticipated 


\section{Table $4 \quad$ Effect of delivery method on returns}

\begin{tabular}{lrr}
\hline & Hand delivery & Postal delivery \\
\hline Households & 3,242 & 3,926 \\
Returns & 387 & 458 \\
Returns, per cent & $11.9 \%$ & $11.7 \%$ \\
\hline
\end{tabular}

positive impact on return rates. Table 4 compares return rates ten days after rehearsal day (just before follow-up started), for a similar sample of hand delivery and post out households.

The postal and hand delivery return rates are very similar. This calls into question the benefit of hand delivery given its extra cost. The conclusion from the 2007 Census Test was that the lower initial return rate from postal delivery could be more than made up through the extra follow-up affordable from the savings post out brings, and hence it was decided that point to post out to at least 95 per cent of households. The rehearsal experience suggests that even 5 per cent hand delivery is not cost effective. By dropping hand delivery to households in 2011 , more effective use of resources can be made through targeted follow-up.

\section{Collection}

\section{Introduction}

For each method of return, it was possible to quickly identify which questionnaires had come back:

- the envelope was designed so Royal Mail scanners could read the barcode through the window while the envelope was in the postal system. This information was then uploaded daily to the questionnaire tracking system

- the householder entered a unique internet access code online. This code was associated with their address. Once they had submitted their questionnaire the information was uploaded onto the questionnaire tracking system

Field staff were quickly and accurately informed which households had returned a questionnaire and therefore did not need follow-up visits.

\section{Paper return process}

The postal process worked well from both a technical perspective (in terms of the receipting) and from a security and confidentiality perspective.

However 21 per cent of returned questionnaires could not be scanned through the envelope window, compared to the 5 per cent estimated, due to questionnaires being the wrong way around in the envelopes. Although manageable with the number of returns for rehearsal, similar proportions would cause significant delays to receipting in 2011 . This could be particularly acute during the days around census day when the volume of postal returns are likely to be greatest. To avoid this, the design of the questionnaire envelope and instructions has been improved.

During the postal return period, there were seven days of industrial action. Royal Mail put into place contingency plans (for example, redirecting census mail elsewhere for sorting) to reduce disruption and the impact of the strike action was minimised on the rehearsal operation. It did provide the opportunity to assess Royal Mail's contingency plans and to make changes for 2011. 


\section{Internet returns process}

The overall user experience was good, evidenced by the low level of drop out from the online questionnaire (89 per cent of people starting the questionnaire made a submission). The average length of time for a household to complete an internet return was 27 minutes (average household size of 2.5 people).

The rehearsal identified a number of small improvements to the website design and underlying validation and routing. For example, in some instances when users went back to correct previous answers, the routing through the questionnaire did not change appropriately.

The proportion of people (8 per cent) responding online was disappointing. The assumption for 2011 is that 25 per cent of returns will be completed online. The lower proportion may be due to the types of areas chosen for the rehearsal. Preference from the internet option was higher amongst students and in city areas.

Lack of awareness seemed to be the reason for not using the internet option, rather than the site or channel itself. Respondent surveys revealed that awareness of the online option was relatively low at 45 per cent. The questionnaire and follow-up literature did not make the internet sufficiently prominent. This is being changed for 2011; the internet option is now more prominent on the questionnaire and supporting materials.

Links through to the website from other sites and search engines were not as high profile as they will be in 2011. The limited scope of the rehearsal meant it was not worth paying for promotion that could not be geographically contained. A strategy for making the website more prominent on search engines has been developed for 2011. Similarly many local authorities and key stakeholders have already put links to www.census.gov.uk on their websites with many more expected to follow shortly.

\section{Nature of internet respondents}

The differences between internet and paper respondents have been examined. Figure $\mathbf{5}$ shows the breakdown of the age of respondents using each completion method.

\section{Figure 5 Return method by age group}

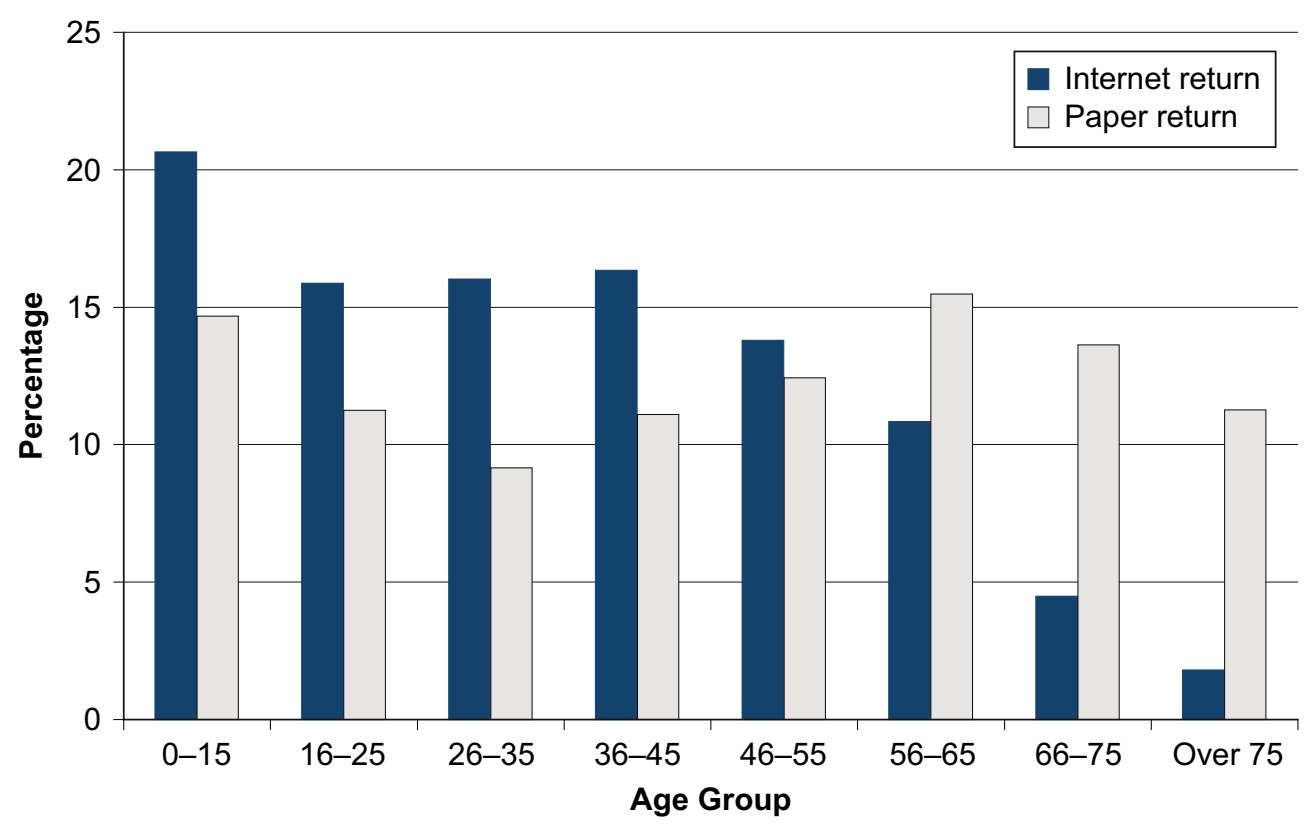


Figure 5 shows a clear trend. A greater proportion of young people used the internet (or had their return made online by parents). Differences in responses to questions are typically linked to this, for example more internet respondents were from single people and/or students and more paper respondents were widowed or retired. Another trend identified was that more affluent people used the internet (households responding by the internet were more likely to have two or more cars).

\section{Follow-up}

\section{Design of process}

Collectors were scheduled to begin visiting non-responding households on 21 October 2009, 10 days after rehearsal day. The enumeration design is based around evidence that most of the population will return their questionnaire without any prompting. Follow-up is the process of visiting non-responding households to either provide assistance with completing the questionnaire, or persuading the householder to do it themselves.

The receipting process identified responding households and updated the QT system. Follow-up lists of non-responding households were printed from the QT system by the coordinator. These lists were provided to collectors who were instructed on the amount of hours to spend in each area. Areas with low return rates were prioritised ahead of those with (comparatively) high return rates.

\section{Results in terms of impact on returns}

Table 5 shows the return rate at day ten and at the end of the rehearsal for each hard to count stratum.

\section{Table $5 \quad$ Effectiveness of follow-up by hard-to-count strata}

\begin{tabular}{lrrr}
\hline Hard to count strata & $\begin{array}{r}\text { Return rates at start } \\
\text { of follow-up (day 10) } \\
\text { (per cent) }\end{array}$ & $\begin{array}{r}\text { Final return } \\
\text { rates } \\
\text { (per cent) }\end{array}$ & $\begin{array}{r}\text { Improvement } \\
\text { from follow-up } \\
\text { (per cent) }\end{array}$ \\
\hline HTC1 & 38 & 52 & 14 \\
HTC2 & 30 & 47 & 17 \\
HTC3 & 20 & 37 & 17 \\
HTC4 & 12 & 28 & 16 \\
HTC5 & 10 & 25 & 15 \\
\hline
\end{tabular}

This shows that the follow-up operation increased return rates fairly evenly across HTC strata. However, especially in HTC4 and 5, it was not successful in increasing return rates sufficiently. Given this, follow-up resource for 2011 is being increased, especially in hard to count areas, so the operation is better able to cope with low day 10 return rates. Also, the number of coordinators in HTC4 and HTC5 areas is being increased so they manage teams of 12 instead of 15. In addition to giving staff more management support and time, this makes it practically easier to increase resources in the operation if needed.

\section{Calling patterns}

Success at follow-up is measured by the collector's ability to secure a return from a household. For this to happen, they first need to be able to make contact with a householder. Collectors were instructed to visit households at different times of day and on different days of the week. Table 6 shows the rate of success at making contact for three different blocks of the day (based on a sample of collectors). 


\section{Table $6 \quad$ Success at contact}

\begin{tabular}{lrr}
\hline Time & $\begin{array}{r}\text { Per cent } \\
\text { of visits }\end{array}$ & $\begin{array}{r}\text { Per cent } \\
\text { of contact }\end{array}$ \\
\hline Weekday 8am - 4 pm & 53 & 22 \\
Weekday 4pm - 6pm & 14 & 28 \\
Weekday 6pm - 8pm & 4 & 24 \\
Weekend & 28 & 29 \\
Overall & 100 & 25 \\
\hline
\end{tabular}

It is clear from the table that follow-up visits are more successful in late afternoons/evenings and weekends. This is consistent with research and information from other social household surveys that ONS conducts.

The table also shows that 53 per cent of the visits were made during the day on weekdays, a proportion that was far too high to provide the best chance of making contact and securing a questionnaire. One reason for this was the timing of the rehearsal. British Summer Time (BST) ended on 25 October 2009, four days after follow-up started. This reduced the light available in the evenings and collectors were less willing to work in the dark. For the 2011 Census this will be less of an issue as it will be light in the evening for the whole follow-up operation (BST starts on 27 March 2011).

Another issue was the particular contracts of the collectors. They were contracted to work for either 15,25 or 35 hours a week. Depending upon the distribution of contracted hours within an area this will have contributed to more visits during the day - staff working longer hours inevitably had to do some during the daytime.

This has resulted in:

- changing the collectors' instructions to be more prescriptive about visiting times and calling patterns

- reviewing the training materials for coordinators and whether there are any further tools that can help them spot irregular calling patterns

- reviewing the distribution of contracted hours within an area and whether the recruitment process can support recruitment of specific hours in specific locations

\section{Conversion of contact into a return at follow-up}

Based on a sample of non-responding households successfully contacted during the rehearsal, 18 per cent made a return, 17 per cent refused to participate and the remaining 65 per cent subsequently failed to make a return. The census is compulsory, giving the collectors additional leverage. However, relying solely on this to improve this success rate cannot happen and two distinct actions underway are:

- reviewing the recruitment criteria for collectors and whether some experience of cold calling or doorstep work can be considered without significantly increasing the risk of not recruiting enough people in the right places

- improving training and instructions to equip collectors with persuasion tools 


\section{Managing return rate variability}

One of the key aims of the field operation is to minimise the variation in return rates within each HTC stratum within a local authority. This is an important factor for producing accurate local authority population estimates. To achieve this, coordinators were tasked with managing variation in return rates using the reports generated by the questionnaire tracking (QT) system. These reports informed the coordinators how many hours of effort should be directed at each workload, based on return rates across the local authority, to reduce the differentials.

In many areas the field force proved unsuccessful in reducing variation in return rates. For 2011, the instructions have been made clearer on the tasks required, the context of why reducing variability is so important - these messages did not feature strongly enough in the rehearsal instructions and training.

\section{Field initiatives to improve return rates}

From early on in the follow-up period it was apparent that return rates were lower than expected, especially in Newham. A number of actions were instigated to boost return rates, all similar to some of the actions planned for 2011. These additional actions had mixed success in improving response (although success was difficult to measure given the rehearsal's voluntary nature).

\section{Additional follow-up resource}

An extra 300 follow-up hours were deployed in Newham (an increase of around 20 per cent). It is not possible to directly quantify the impact of the additional hours as this was contracted very early in the follow-up operation. These extra hours were to keep workloads at the intended size; without extra resource workloads would have increased because of lower initial return rates.

\section{Targeted reminder letters}

Four weeks after rehearsal day, 14,000 addressed reminder letters were sent to non-responding addresses in three coordinator areas in Newham. Non-responding households in two areas received a letter asking them to respond, the third area received the same letter with, additionally, a replacement questionnaire. The results of this are shown in Table 7.

\section{Table $7 \quad$ Return rates after 9 November in Newham}

\begin{tabular}{lr} 
Action taken & $\begin{array}{r}\text { Return rate after } \\
\text { 9 November } \\
\text { (per cent) }\end{array}$ \\
\hline Reminder letter & 11.1 \\
Reminder letter with replacement questionnaire & 11.7 \\
No reminder letter & 7.2
\end{tabular}

Return rates, after the reminder letters were delivered, were considerably higher. Sending a replacement questionnaire yielded a slightly better return rate than just sending a letter. In light of these results, reminder letters will be sent to non-responding households in the hardest to count areas in 2011. Some of the supporting follow-up processes will be changed to make this easier to implement, particularly on a wider scale. Replacement questionnaires will not be sent as it is not cost effective for the slightly higher return rate achieved. 


\section{Management of the field operation}

The rehearsal provided a good opportunity to rehearse procedures for managing and responding to low return rates. Operational responses to particular operational issues, particularly low returns, need to be fully developed and ready to implement immediately.

\section{Communal establishment enumeration}

\section{Design of the process}

Few changes have been made for communal establishments (CEs) from 2001's design.

In simple terms, the process for enumerating CEs was:

- questionnaires were delivered to the manager or person in charge of the establishment by a special enumerator (special enumerators only cover CEs - not households - and so are specifically trained for the different procedures required)

- the CE questionnaire (which asks questions about the accommodation characteristics) was completed by the CE manager

- individual questionnaires were delivered to individual residents by the CE manager

- residents completed a paper questionnaire or an online return

- the special enumerator returned to collect the completed questionnaires after census day and to help resolve any queries

This process varied for larger establishments. In these there was a degree of liaison before the operation and/or the enumeration was handled by the census coordinator rather than a special enumerator. Also, the contact and interaction between residents and the special enumerator varied depending on the nature of the establishment and the level of involvement of the CE management.

\section{Findings}

Overall, the processes for enumerating communal establishments worked well. In particular:

- the use of specific staff to enumerate CEs

- the distribution and collection of questionnaires to field staff and to CEs

- the estimation of staff numbers required and workload planning

No particular problems were encountered at boarding schools, hotels or prisons

In general, procedures worked for encouraging participation from CE managers but were less effective for obtaining responses from individuals within CEs. Return rates from CE residents are set out in Table 8.

\section{Table 8 Communal establishment return rates}

\begin{tabular}{lccr}
\hline Type of residents & $\begin{array}{r}\text { Questionnaires } \\
\text { issued }\end{array}$ & $\begin{array}{r}\text { Questionnaires } \\
\text { returned }\end{array}$ & $\begin{array}{r}\text { Return rate } \\
\text { (per cent) }\end{array}$ \\
\hline All CE residents & 12,818 & 3,567 & 28 \\
CE residents (excluding student halls) & 4,536 & 2,247 & 50 \\
Student hall residents & 8,295 & 1,320 & 10 \\
\hline
\end{tabular}


The overall return rate from CEs was lower than expected, even when the return rates of the universities are excluded. A range of generic issues was encountered in enumerating CEs:

- management information on progress was lacking. The QT system, which worked effectively for households, is based on receipting questionnaires when returned through the postal system - this does not apply to questionnaires from CEs. Replacement manual processes did not work or are not scalable for 2011. The need for action to address return rate problems was not identified, or was identified too late

- the collection phase clashed with the preparation and start of household follow-up and coordinators did not have sufficient time to manage both effectively

- a number of large CEs were incorrectly identified from the address check as having usual residents and/or the estimated number of usual residents was inaccurate

\section{Caravan sites}

The collection of census data from caravans sites is complex, due mainly to the census definition of a 'usual resident'. Site managers and people living in caravans can have a negative attitude to the word 'resident'. Resident has inferences regarding licence restrictions and council tax liability and as such, residents can be reluctant to participate. Some caravan site managers denied having residents on site - contrary to other indications. Some managers also disliked and discouraged special enumerators walking around their site. Simplified and straightforward instructions regarding the enumeration of caravan sites are required to elicit better response rates (together with advance publicity addressing the council tax issue). Preparatory work by area managers will be very important to resolving these issues before enumeration.

\section{University halls of residence}

The return rates from students in university halls of residence were very disappointing as set out in Table 8. Students, as a group, traditionally present a challenge to achieve high return rates.

The level of support from universities was mixed. Many accommodation managers said they were too busy, though some did assist with delivery. Other halls of residence did not have a 'manager' or 'warden' to take responsibility for enumeration of residents, while some field staff were not given access to halls of residence to deliver or collect questionnaires. But, other university managers were helpful in sending out emails to students as a method of publicity, and to remind students to complete questionnaires online.

Where low return rates are expected, good information on non-responders is needed. A variety of tracking methods for questionnaires was used in universities in the rehearsal. None of these proved particularly effective and, in some cases, a substantial amount of time was spent setting up a manual system which achieved little result.

In light of this, the processes for enumerating student halls in 2011 is being improved by:

- liaising with each university to determine the best way to enumerate student halls - taking into account variations in term times and access arrangements

- associating questionnaires to individual rooms within student halls to enable more effective follow-up of non-responders. 


\section{Care homes}

Some issues arose at care homes with a number of managers saying they were unwilling to help with completing questionnaires as it conflicted with residents' Power of Attorney appointments. In such situations, questionnaires were posted out to the relative in question for completion. This approach was time-consuming and makes follow-up difficult.

\section{Recruitment, pay and training}

\section{Overview}

This section covers the recruitment, pay and training of field staff (including staff for the Census Coverage Survey) which was conducted by Capita (RPT contractor). These processes worked relatively smoothly and without serious issues; however, this is an area where the sheer scale of the operation for 2011 (around 35,000 field staff) means there will always be risks.

\section{Recruitment}

The recruitment of field staff was a success with the required number of staff recruited. In the main, the mix of staff represented the composition of rehearsal communities. The required proportion of Welsh speakers was recruited in Anglesey (58 per cent).

The overall quality of field staff recruited was assessed as high - probably higher than will be achieved in census (due to a wider choice of applicants for rehearsal). Staff who dropped out either during the recruitment process or while in post were successfully replaced via the rapid replacement process.

\section{Pay}

The payroll worked well. Staff who submitted timesheets on time were paid on time. The vast majority of staff $(300+)$ used the online system to submit their hours worked. For staff unable to submit their hours online there was an Interactive Voice Recognition (IVR) alternative system; this was used by four people.

\section{Training}

The training package that field staff received was a blend of paper instructions, e-learning and classroom training. For 2011, this will be supported by a DVD. The instructions provided information that the field staff needed to know for their role. The e-learning was built on the knowledge base acquired from the instructions; testing understanding and providing information to stimulate learning and retention of knowledge. The classroom training focused on 'soft' skills to instil staff with confidence and understanding of their role.

Some changes to content of training will be needed to reflect lessons learned about field processes (see above).

\section{Public Engagement}

\section{Introduction}

ONS's public engagement activities for the rehearsal were designed to raise awareness among the general population and were also directed at specific segments of the population. This section covers both the activities to target/contact the population (publicity, community and local authority engagement) and those services offered to the public if they contacted either the census telephone helpline or online help. 


\section{Publicity}

\section{The design of the campaign}

The publicity campaign put together for the rehearsal was designed to best trial what will be done in 2011. Inevitably this could not be a complete prototype as certain media were ruled out (TV, many radio stations and newspapers) as their geographical reach was wider than the rehearsal areas and therefore potentially many people could have been confused. A number of different media were used:

- local radio

- local press

- billboards and posters

- internet advertising

- advertising on pizza boxes, beer mats and take away lids

The main messages were:

- the census is happening

- the rehearsal is happening and why

- the value of the census in planning services for the future

- the need to make a return

- the online option

- the confidential nature of the census.

\section{Results}

The impact of the publicity campaign was assessed using surveys carried out before and after the campaign. The main findings from this were:

- a high proportion of people recalled seeing adverts

- there was higher awareness of publicity using traditional media (press, posters and radio) than online media (though these worked with students)

- positive media coverage had as much impact as advertising

Interviews were conducted in rehearsal areas before and after the publicity campaign; this showed that:

- awareness of both the census and rehearsal grew

- awareness of the online completion option grew from 16 to 45 per cent

- understanding of the purpose of the census grew but was still low

- trust in ONS and the confidentiality of the census grew.

Publicity did improve awareness of the census and attitudes to it, but the level of likelihood to complete a return differed by age and ethnicity, as set out in Table 9. 


\section{Table $9 \quad$ Likelihood to complete a return before and after the publicity campaign}

\begin{tabular}{lrr}
\hline & $\begin{array}{r}\text { Very likely to complete a } \\
\text { return in 2011 BEFORE } \\
\text { publicity campaign } \\
\text { (per cent) }\end{array}$ & $\begin{array}{r}\text { Very likely to complete a } \\
\text { return in 2011 AFTER } \\
\text { publicity campaign } \\
\text { (per cent) }\end{array}$ \\
\hline Ethnicity & & \\
White & 86 & 90 \\
Asian & 70 & 72 \\
Black & 80 & 75 \\
Age & & \\
$18-24$ & & 75 \\
$25-34$ & 68 & 84 \\
$35-54$ & 80 & 88 \\
$55+$ & 85 & 93 \\
\hline
\end{tabular}

These trends are in line with expectations and the analysis of respondents set out above. Older people and white ethnic groups are more likely to make a census return without any further action from ONS.

\section{Improvements for 2011}

In light of analysing the rehearsal, the following improvements are being made:

- more resource is being put into advertising and publicity

- clearer, simpler and bolder messaging (much easier in a national, compulsory census than a localised, voluntary rehearsal)

- further targeting of messages at target population groups.

\section{Community and local authority liaison}

\section{Introduction}

It is hard to calculate the precise impact of publicity on return rates but, by comparison to other tests ONS has conducted with no publicity, it is estimated that publicity increased rehearsal return rates by 2.3 per cent.

ONS engaged both with local authorities in the rehearsal areas and community groups, before and during the operation. Similar to publicity, this was to help the rehearsal run smoothly and to test initiatives for 2011.

\section{Local authority liaison}

Prior to the rehearsal, ONS had face to face meetings with each local authority to explain plans, identify supporting activities and respond to any concerns. Thereafter most of the engagement with local authorities was done through the area managers.

Overall the rehearsal reinforced the view that good working with local authorities is crucial to making the operation successful in terms of practical support, endorsement and drawing on local expertise. The main issue encountered in the rehearsal (lack of time for the area managers to 
build on knowledge and advice from local authorities) will be less relevant in 2011 because area managers start eight months before the event rather than three for the rehearsal. Additionally, in response to local authority feedback the number of area managers has been increased from 118 to 157. They will typically be covering smaller areas than previously planned.

\section{Community liaison}

Engagement with community groups, while achieved, suffered from the same issue as local authority engagement: lack of time for the local field staff to build on contacts and develop the networks needed. That said, contact was made with all necessary key target population groups in each of the areas. All the communities were encouraged to engage. All community groups who were met or contacted were supportive, but it is hard to assess how effectively they publicised the census message.

In response to these findings the recruitment of a team of community advisors (CAs) specialising in different community groups has been brought forward. They will be based where these groups are geographically clustered and work with the area manages to promote the census messages. Where possible, they will speak languages spoken locally. The groups to be covered by the CAs include the Indian, Pakistani, Bangladeshi, Black African, Black Caribbean, Bangladeshi and Chinese communities. In the event of area manager turnover, the CAs will provide continuity in community engagement. Plans for engagement with gypsies and short term migrants are being developed further.

\section{Census telephone helpline and online help}

\section{Background}

As in previous censuses a telephone helpline for the public to call was available and the rehearsal had extensive online support. The online help offered great opportunities to provide much more information to the public than is practical in paper, for example extensive background notes about the census and why it happens, advice on completing the questionnaire and translation support available.

\section{Census telephone helpline}

The telephone helpline met all its quality objectives and provided a good, efficient service to the public. Little change to services is planned for 2011 apart from scale related ones. However some assumptions are being reviewed. Fewer calls than expected were received, but more needed operator assistance. Fewer calls could be due to the use of the online help and/or that the questionnaire and accompanying literature explained the task. If this is correct this trend should continue for 2011. However, it may well be rehearsal specific factors; the voluntary nature of the rehearsal may have meant that some people who will need assistance in 2011 decided not to respond. Similarly those with concerns about confidentiality, or other issues, may have not engaged with the rehearsal. In 2011 they will need re-assurance.

\section{Online help}

In total the website received over 9,000 visits during the rehearsal operation. The most popular queries/visits related to:

- how to complete a return online (10 per cent)

- what is a household (7 per cent)

- who to include on the questionnaire (7 per cent) 
- who should complete the questionnaire (7 per cent)

- what to do if away on rehearsal day (6 per cent)

Going forward to 2011 , online help is clearly going to be valuable to the public. More information will be available, so it needs to be easy to navigate. A review of the way people enter the site will take place, to make sure it is easily found from related areas of the internet.

\section{Conclusions and ONS response to the rehearsal}

\section{Conclusions}

The rehearsal was a success. It provided a good opportunity to test systems and procedures. Mostly the operational procedures and supporting systems worked well. Although return rates are difficult to predict for a voluntary exercise, the rehearsal rates are considerably less than expected. The low return rates provided a significant and timely reminder that ONS should not be complacent. The overall census design has therefore been reviewed to ensure it is in line with the quality objectives.

The main conclusions and lessons learned from the rehearsal were:

- the address register developed was of sufficient quality for the rehearsal but not for the 2011 Census. The measures being taken will improve quality and in particular reduce under-coverage

- the printing process worked well. The complexity and scale of the task means more time is needed for quality assurance

- the post out and post back operations worked smoothly

- hand delivery to households did not improve return rates, or reduce the follow-up workload

- internet data capture worked well technically. It was easy to use

- internet return rates were low. More promotion is needed

- the questionnaire tracking system worked effectively and enabled the identification of addresses for follow-up

- the follow-up procedures need tightening to ensure the field staff call at appropriate times, are effective at converting contact to returns and workloads are planned to reduce variability

- the procedures for the enumeration of student halls were not effective. These are being redesigned

- more time was needed for area managers and coordinators to effectively carry out their roles

- the publicity campaign did reach people, more is needed. It will be clear and targeted

- more community engagement is needed

- the online help and telephone helpline effectively supported the public

\section{Actions ONS is taking following rehearsal}

In response to these findings, a number of changes to the 2011 plans are being made:

- increasing the follow-up resources 
- putting a greater proportion of those resources into the areas that are particularly challenging to achieve high return rates

- increasing publicity spend

- increasing community engagement activities. Community advisors will be appointed to work with target population groups to raise their understanding and trust.

- reducing hand delivery to just communal establishments. Hand delivery to households has a minimal effect on return rates and that resource is better spent on follow-up

The rehearsal has identified numerous improvements that need to be made in particular to focus the field process and training, to increase online completion and to make the address register more accurate. As a result of the rehearsal, internal costs and assumptions have been reviewed. Savings have been identified that can be used to fund the improvements outlined in this report.

The evaluation of the 2009 Rehearsal was published on the Census website in May 2010 at: www.ons.gov.uk/census/2011-census/2009-census-rehearsal/evaluation-of-the-2009-rehearsal.pdf

\section{References}

1 Compton, G (2008) '2007 Census Test : Evaluation and key objectives', Population Trends 132: 26-33. 